\title{
Ministério da Cultura saiu na frente e fez sua reforma
}

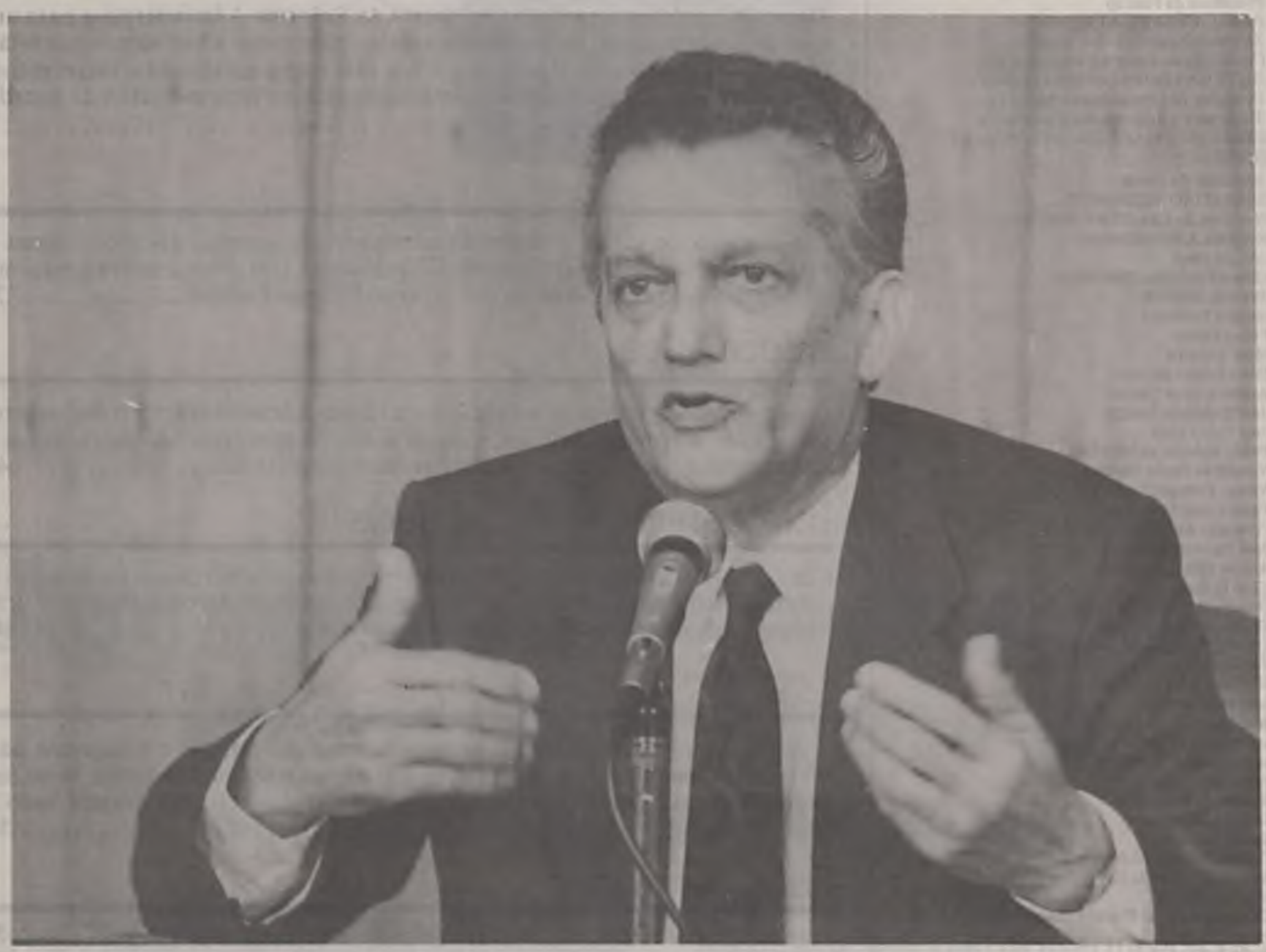

O ministro Celso Furtado, como planejador, trocou a horizontalização pela verticalização

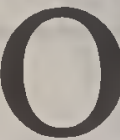

\section{Ministério da Cultura}

foge ao comum dos ministérios, em estrutura e concepçăo de politicas que pratica. Ė o resultado de ter um ministro-economista e planejador, que consegue enquadrar em ações dirigidas as abstrações do ramo. E a reorientaçăo de sua estrutura foi obra de apenas um mês - quando Celso Furtado assumiu, faltavam trinta dias do prazo de um ano dado pelo Presidente da República para sua implantação. O novo ministro teve de ir ao Ministério da Administração e convencer a burocracia de que há diferenças fundamentais entre um ministério pequeno e voltado para atividades superiores e um ministério grande, como o dos Transportes, por exemplo, que cuida de açōes mais quantitativas do que qualitativas. Mas ao passar para o seu projeto essa reforma administrativa setorial, Furtado tirou sua pasta da horizontalização que amarra os demais ministérios a órgăos centrais de planejamento e, por isso, têm as politicas geralmente planejadas fora de suas jurisdiçōes. O resultado é que as politicas praticadas, daqui para a frente, no campo cultural, têm atividadesfins e atividades-meios claramente separadas. E mais: a aplicação dos recursos liberados, oriundos do Governo e do particular, será feita pela sociedade, pelas comunidades artisticas beneficiadas. Essa diretriz vale inclusive para os investimentos a serem feitos com os recursos resultantes dos incentivos fiscais destinados à cultura criados pela Lei Sarney. Nessa entrevista, o ministro Celso Furtado analisa também como a reforma administrativa pode representar um salto cultural para o Pais. 
SP - Há informações de que o senhor deu uma mexida no Ministério da Cultura, criando estruturas diferenciadas daquelas que sustentam as demais pastas do Governo. Quais foram as mudanças mais importantes?

Celso Furtado - não houve mudanças: o Governo havia estabelecido o prazo de doze meses para a implantação do Ministério. Quando assumi, faltava apenas um mês para se esgotar esse prazo. Tive de monlar a estrutura e dar uma organização ao Ministério, que é um caso particular. Menos que uma reforma administrativa, que não se pode fa$7 \mathrm{cr}$ num ministerio isolado, tivemos de criar uma estrutura condizente com os objetivos. Fui professor de macroadministração no passado, sou formado como técenico em administraçĩo, especializado em organização. Sabia que o centralismo administrativo do regime autoritário criara estruturas que são totalmente inadequadas para o serviço publico brasileiro.

RSP-Por exemplo.

Celso Furtado - A uniformização. Colocara-se na mesma concepção um ministério imenso, como o dos Transportes, e um ministério pequeno, como o da Cultura, o da Tecnologia. Os ministérios já nasceram feitos. E ainda: uma concepçao com a qual eu não concordo, para o serviço público: sistêmica. Conduz a uma excessiva centralização. São os cortes horizontais. Com seus sistemas de planejamento, de administração de contabilidade, tudo dentro de uma visão sistêmica. E isso desarticula o ministério.

RSP-Mas, ministro, o senhor inovou mas não descartou um instrumento do autoritarismo - o serviço de informaçoes, que está na estrutura do MinC como um rastro do regime militar.

Celso Furtado - Esšes dispositivos foram criados em 1975 por decreto,e o Ministério da Cultura tam. bém ainda tem um serviço de informaçðes. Mas esses serviços, com a Nova República, evoluiram muito. Primeiramente, tivemos a iniciativa de indicar um civil para a chefia, com o apoio inclusive do generalchefe do SNI. É uma função civil e tem de ser ocupada por elemento de total confianca do ministro - se não houver essa confiança, o ministro tende a não usar o seu serviço de informações.

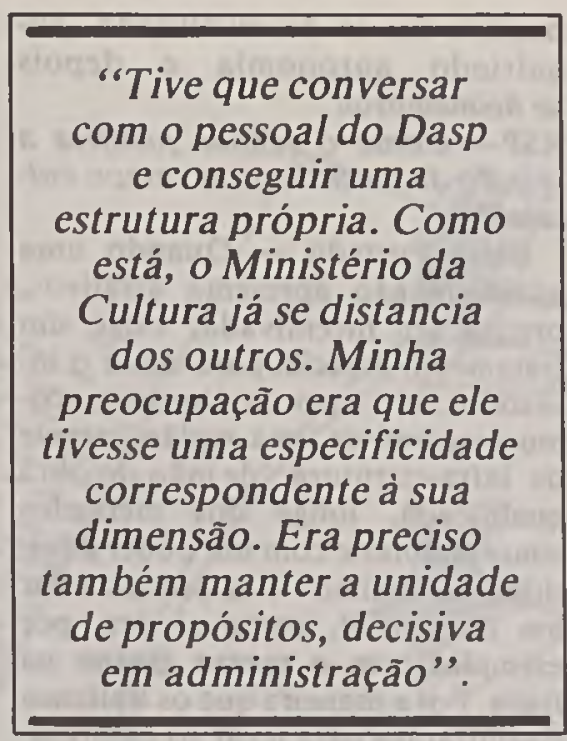

RSP-Afinal, o que é diferente no MinC?

Celso Furtado - A própria organização interna do ministério. $O$ sistema de planejamento no Brasil obedece a normas rigidas e préestabelecidas, emanam de órgão central, quando o planejamento tem de corresponder à especificidade do órgão. É fácil compreender que o planejamento, no Ministério dos Transportes, é totalmente diferente do que se deve praticar no Ministério da Cultura. No primeiro, quase tudo é quantitativo, no outro é quase tudo qualitativo. Num caso é objetivo, no outro caso é subjetivo.

RSP - Quais os problemas operacionais mais importantes que o senhor encontrou no Ministério da Cultura?

Celso Furtado - Ao se desarticular totalmente um ministério, submetendo-o a sistemas horizontais, seu titular não tem uma visão do que se passa no Ministério. Com isso, inexiste a unidade de propósito na formulação de políticas, que é um principio fundamental de administração. Se a organização é corta$\mathrm{da}$, horizontalmente, em fatias, submetida a centros de decisão situados fora do Ministério, è evidente que cssa unidade de propósito desaparece. E assim eu tive de discutir com o pessoal do Dasp (antigo Departamento de Administração do Serviço Público, hoje transformado em Secretaria do Pessoal Civil do Ministério da Administração) e consegui uma estrutura própria. De maneira que, como está, o Ministério da Cullura já se distancia dos outros ministérios. Minha preocupação, desde o começo, era que o Ministério tivesse uma especificidade correspondente à sua dimensão.

RSP - É verdade que o senhor virtualmente abstraiu a figura do secretário-geral, que era uma espécie de vice-ministro?

Celso Furtado - O secretáriogeral era alguém que representava um pólo de decisão, tanto substantiva como adjetiva. Isso me parece inadequado, particularmente num ministério pequeno. Havia outros casos de falta de limitação clara entre atividades-fins e atividadesmeios, que é outro principio fundamental de administração. É preciso haver unidade de comando nos meios e de politica nos fins.

RSP - No caso do MinC, como se definem as atividades-meios $e$ as atividades-fins e como se estabelece $o$ comando de umas e de outras?

Celso Furtado - Há muitas funçôes no Ministério, mas seu fim maior é o da prática de uma politica de desenvolvimento cultural. Mas há fins específicos, como a defesa do patrimônio cultural, a preservacão de sua memória cultural, o apoio à produção cultural, a difusão dos valores culturais etc. Exige-se que haja uma organização em funcão desses fins. Os meios, no entan10, são comuns a todos os ministérios, que são mais de vinte. Podem até ter uma unidade de comando, o que é inclusive o principio de economia. Na organização que encontrei, não havia limite entre as atividadesmeios e as atividades fins enão havia separação entre elas, como ainda hoje não existe.

RSP - E como ficou o secretáriogeral ma nova estrutura do MinC?

Celso Furtado - O secretáriogeral devé ser responsável por loda a organização dos órgãos-meios, em nosso Ministerrio. Nos demais ministérios, o secretário-geral tanto administra os órgãos chamados adjetivos como os órgãos substantivos. O que se fez aqui, em apenas um mês, foi uma tentativa de reforma administrativa, um esforço de reformar a organização em busca de uma estrutura específica, para o Ministerio da Cultura. Mas esse esforço não cobre a superficie de uma reforma administrativa geral. Esta implica numa definição clara de objetivos e depois de funçðes, a nivel de pessoal, com carreiras e com a classificaçao de cargos rigorosa. 
RSP-Como o senhor vê o servidor público de uma administracão transparente, como a projetada pela Nova República, após a reforma administrativa?

Celso Furtado - Eu vejo a geracão de um corpo de funcionários que sejam, de verdade, responsáveis e não como empregados que os ministérios têm hoje em dia, em grande parte. São CLT, que hoje podem estar aqui e amanhā não estarem mais, como se trabalhassem para empresas e fossem descartáveis.

RSP - O regime juridico único resolveria esse problema?

Celso Furtado - É essencial. Volta-se à idéia clássica do estatuto do funcionário, no qual ele não é um empregado qualquer. $\dot{\mathrm{E}}$ alguém que lida com a coisa pública. Ele sabe que sua repartição é julgada pela opinião pública e que, pela sua ineficiência, pode desaparecer. $\dot{E}$, portanto, um fiel depositário da confiança do público, da Nação. Tem uma carreira diante de si e um futuro a preservar. Ele se liga a essa carreira e dela não se afastará, senão por motivos excepcionais. O empregado deixa sua empresa a qualquer momento e é substituido por outro imediatamente. São duas concepcões totalmente distintas em organização de pessoal. Nos anos da ditadura, pretendeu-se imaginar que o principal era apenas a eficiência, adquirida a qualquer custo, quando, na administração pública, a eficiência só se obtém pela consciência da responsabilidade.

\section{CULTURA INCENTIVADA}

RSP_ Desde os tempos da Sudene, sua imagem está ligada aus incentivos fiscais. Essa polficia de incentivo à cultura estál lastreada nos mesmos principios quc' c'stimularam a industrializacio do Nordeste?

Celso Furtado - A idćia ć recditar, na cultura, o papel exercido pela Finep (Financiadora de Projetos que surgiu como agência do Banco Nacional de Desenvolvimento Econômico e cresceu de tal mancira que se tornou uma cmpresa independente). A Finep é um banco que investe em pesquisa $c$, pelos bons resultados obtidos, tende a servir de modelo. Havia, no Banco, um princípio de que toda empresa beneficiária dos seus financiamentos teria de destinar parte destes à pesquisa. Esse dis- positivo foi-se desenvolvendo, adquirindo autonomia e depois se desmembrou

RSP - Como o senhor justifica a criacão de incentivos no campo cultural?

Celso Furtado - Quando uma atividade não apresenta atrativos, precisa ser incentivada, exige um tratamento especial para atrair o investidor. No caso do Nordeste, como desenvolver uma região carente de infra-estrutura, de mão-de-obra qualificada, longe dos mercados consumidores e com um poder aquisitivo baixissimo? Era preciso criar um diferencial, como se fez, por exemplo, com o mezzo giorno na Itália. Foi a maneira que os italianos encontraram para levar os empresários a investirem no sul do país, trocando-o pela região norte, onde estavam todas as atratividades, inclusive as chamadas economias externas.

RSP - Em que entra a cultura nessa história econômica?

Celso Furtado - Trata-se de uma atividade que não oferece atrativos ao investidor. Os riscos são enormes - um filme, por exemplo, quando muito, paga o investimento. No caso da cultura, a idéia é simplificar ao máximo o processo, a aplicação dos recursos. A sociedade é que deve, ela mesma, aplicar os incentivos, gerir os recursos. Porque a cultura é criada com a participação de todos. $O$ governo interfere apenas para dar apoio, para incentivar. Essa descentralização máxima o governo a obtém através dos incentivos. A partilha dos recursos se faz entre o particular e o governo, mas sua aplicação é feita por aqueles que dela se beneficiam.

RSP - Não se corre o risco de acontecerem desvios, como ocorreu em outra época em setores de atividades incentivadas, de que o exemplo mais recente é o da Zona Franca de Manaus?

Celso Furtado - Esse risco ocorre, como ocorre também o de os impostos não serem pagos. O governo está ai tentando estancar a evasão de impostos, a sonegação. No caso da cultura, o dinheiro vai ser entregue a instituições devidamente cadastradas aqui no Ministério e devem demonstrar que são competentes para gerir os recursos a elas confiados. E têm de apresentar resultados. Ocorrendo desvios, serão aplicadas punicões muito duras, inclusive com a reclusão dos seus autores.

RSP - O senhor tem também a imagem do planejador, do organizador, do economista de visão inovadora. Lidando com cultura, não parece que está fazendo o papel do gerente de abstracōes?

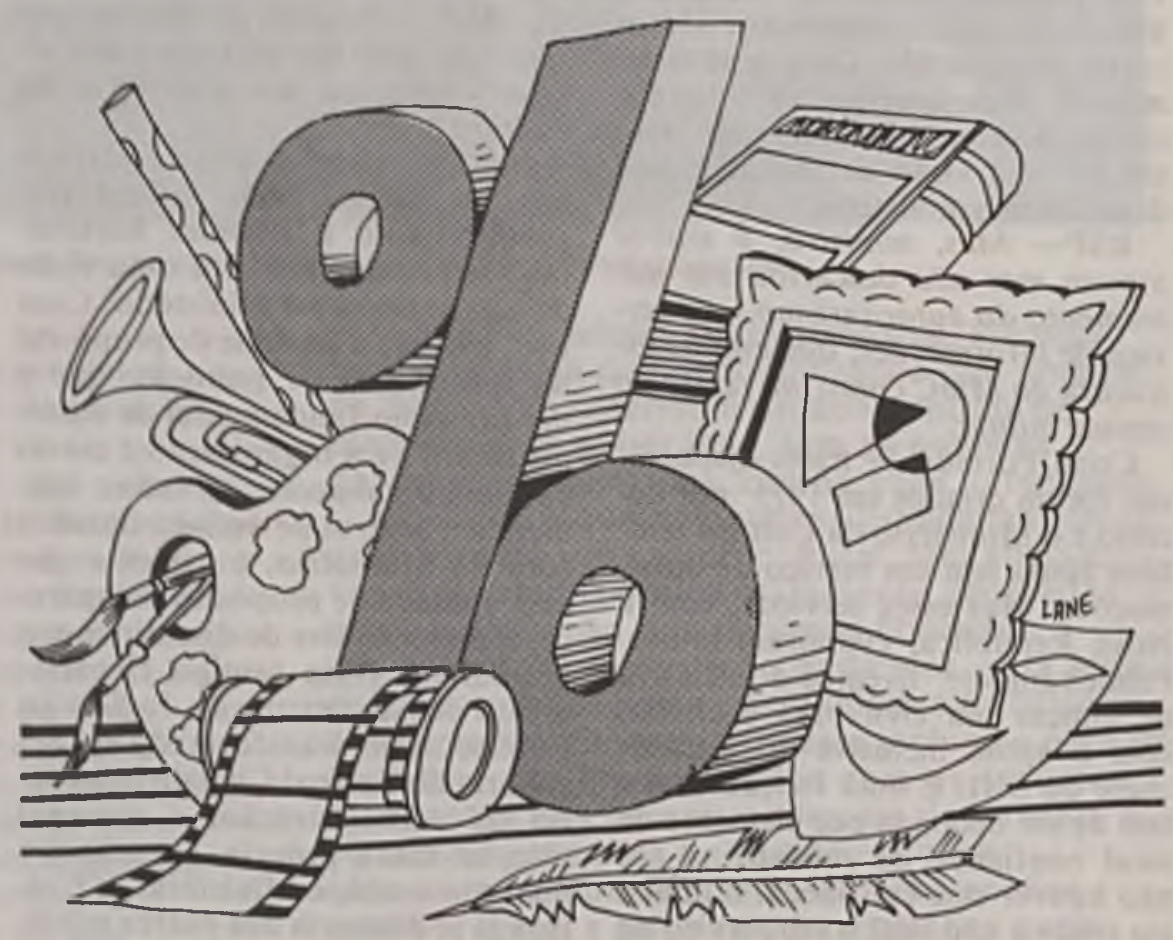


Celso Furtado - Hoje em dia, a vida cultural é objeto de políticas de planejamento. A atividade cultural é tão fundamental para o homem moderno que é decisiva para o seu desenvolvimento. As atividades fundamentais do ser humano, como comer, dormir, quantificadas facilmente, representam o que ele tem de comum com os animais. Já a cultura, como atividade superior, recebe uma atenção crescente nas sociedades modernas. Na medida em que as sociedades se desenvolvem, văo enfrentando problemas novos. Daí o surgimento de instituiç̋es voltadas para o planejamento da cultura, lidando com os indicadores culturais Mas é um planejamento diferenciado, oposto, portanto, àquele que se faz para construir estradas.

RSP - Como é planejar a cultura num País de contrastes como o Brasil?

Celso Furtado - Temos, de fato, uma sociedade desigual, em que a maioria do povo não tem acesso às formas médias e superiores de cultura. E essa massa nem sequer desenvolve formas modernas de atividade, de comportamento. Dai nosso interesse em realizar a difusão cultural intensivamente nesse segmento da sociedade.

RSP - Ministro, num pais de subempregados, como o Brasil, em que os indivíduos têm de empregar todas as horas do dia e parte da noite $\mathrm{em}$ dois ou mais servicos, o senhor não acha que as bibliotecas $e$ os museus deviam abrir aos domingos para garantir a freqüência dos trabalhadores?

Celso Furtado - O problema é que temos poucas bibliotecas e em geral mal localizadas. Precisamos de ter mais bibliotecas e sobretudo bibliotecas funcionais, em todas as instituiçoes. Um dos objetivos do Ministério da Cultura é criar bibliotecas a todos os níveis da sociedade. Os sindicatos dos jornalistas deviam ter bibliotecas, as fábricas deviam ter bibliotecas. Os órgãos públicos deveriam dispor de condiçōes para manter bibliotecas funcionando. Nossa política é de levar o livro a todo mundo, até as prisōes, deveremos ter bibliotecas ambulantes, nas pequenas cidades, nos bairros.

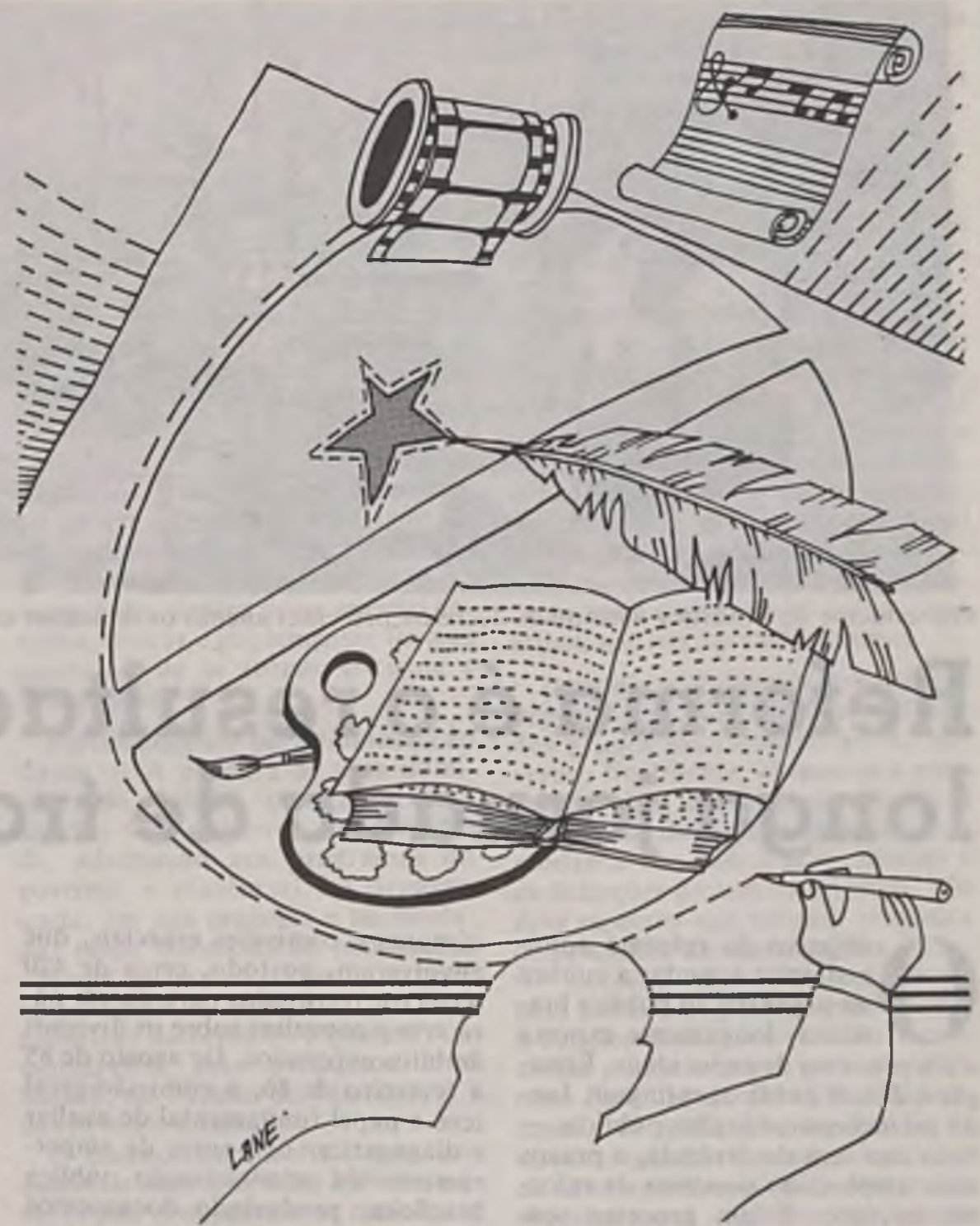

RSP - Ministro, em que uma reforma.-administrativa, do tipo da que se está propondo no Brasil, pode implicar um salto cultural?

Celso Furtado - Uma reforma administrativa visa principalmente dar ao Estado um instrumento indispensável de Irabalho, que é um corpo de funcionários, bem prẹarados, escolhidos pelo sistema do mérito, prestigiados pela sociedade, como já houve no Brasil. E se o Estado fica melhor equipado, é evidente que todas as suas funçōes serão desempenhadas mais eficazmente, inclusive no campo da cultura. O que nos falta, em verdade, atualmentc. $c$ esse instrumento de ação. Se alcancados estes objetivos, é claro que a Naçao atingirá mais rapidamente estágios culturais mais elevados. 